\title{
AN INVESTIGATION OF IMPACT OF VOLATILITY AND BENCHMARK INDEX RETURN ON ETF RETURNS
}

\section{SAMEER SHAIKH ${ }^{1}$, MELBA JUDIETH FERNANDES ${ }^{2}$ AND DEBASIS PATNAIK ${ }^{3}$}

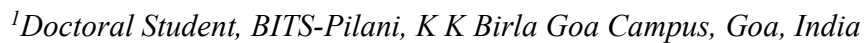

${ }^{2}$ Student, Institute of Cost Accountants of India, Goa Chapter, Vasco, India

${ }^{3}$ Professor, BITS-Pilani, K K Birla Goa Campus, Goa, India

\section{ABSTRACT}

The present study examines the impact of volatility clustering and benchmark portfolio return upon the return of equity exchange traded fund. We employ the GARCH-in-mean model populating 10 equity Exchange traded funds (ETFs) in India, all benchmarking the Nifty50 Index. As passive investment portfolios, ETFs returns exhibited significant clustering of volatility as confirmed by GARCH coefficients. Furthermore, ETFs returns were found to be a function of its benchmark return, results which conform to the structuring of ETFs to passively replicate benchmark returns. Moreover, insignificant volatility coefficients suggest no feedback is received from volatility by endogenous ETF returns. KEYWORDS: ETF Return, Volatility, Index return, GARCH

JEL Classification: G10, G110

Received: Feb 02, 2020; Accepted: Feb 22, 2020; Published: Feb 25, 2020; Paper Id.: IJMPERDFEB202097

\section{INTRODUCTION}

Volatility of financial assets such as stocks and bonds has been a conspicuous attribute of financial markets over a decade now, a feature which defines the degree to which the price of a financial asset, changes over a period of time. Generally, higher volatility implies rapid and large price movements over a relatively short period of time. Financial investors, thereby demand a premium in returns for the additional risk posed by volatility. Studies suggest empirical evidence on the contemporaneous relationship between volume, return and volatility (Richardson, Sefcik \& Thompson, 1987; Lee \& Rui, 2000; Mahajan \& Singh 2008a). Moreover evidence from past research has revealed that the healthy functioning of the stock market has considerable effect on the growth of the economy of a country. For instance, as argued by Mahajan \& Singh (2008a), efficient financial markets stimulate economic modernisation and macroeconomic stability. The volatility phenomenon thus has grabbed the attention of financial institutions, domestic and foreign investors and financial regulators. Exchange Traded Funds (ETFs) being financial asset, also exhibit volatility. Exchange Traded Funds unlike open-ended mutual funds encompass a basket of securities that are traded on the stock exchange. Such funds track an index, bond, commodity, or a basket of assets like an index fund. An index fund in contrast to ETF is a mutual fund designed to mimic the performance of financial market index. ETFs are usually subject to higher trading costs as they trade intra-day like stocks. While the first ETF emerged in the United States in 1993, the Indian investors were lured by its first ETF (Nifty BeEs, launched by Benchmark Mutual Fund) in the year 2002. The growth numbers of such passive investment instrument has been phenomenal since then. In terms of funds mobilised, Indian equity ETFs have grown at a 
compound annual growth rate of 22.34 percent between the years 2007-08 to 2018-19, while the corresponding growth rate for the entire mutual fund industry in India has been 15.20 percent. The compounded growth rate for equity ETFs in terms of average assets under management during the same period (35.99 percent) too has outperformed the average assets under management of the Indian mutual fund industry (13.49 percent). The benefits of intra-day trading facility, low cost, price convergence of ETF and Net asset value, lower distribution cost, etc. are reasons which account for the growth of ETF market in India. Being passive investment instruments ETFs endeavour to replicate the price behaviour of its benchmark portfolio, however a faction of authors in the past have documented a divergence in ETF return performance (Lin \& Chou, 2006; Rompotis, 2009b; Aber, Li \& Can, 2009; Chu, 2011; Sinha \& Dutta, 2013). Such variance, phrased as tracking error can be positive or negative, large or small. The present research thus studies to examine the relationship between ETF return, benchmark index return and its volatility.

\section{REVIEW OF LITERATURE}

Documented research in the area of Exchange Traded Funds has largely been focused on its performance in contrast to index funds and benchmark indices. Such performance is analysed by comparing tracking errors. Also known as active risk, tracking error accounts for the difference in portfolio return and benchmark index return. Roll (1992) emphasised the need to examine tracking error before investing into ETFs. Singh \& Kaur (2016) state that ETFs show evidence of meaningful tracking error while attempting to duplicate their benchmark index return. The study covering 12 equity ETFs between the time periods of April 2011 to March 2015, concludes that while volume and assets under management positively affect the tracking ability, volatility contributes negatively.

Athma \& Kumar (2011) in studying the trends and progress made by ETFs as against Index funds in India during the period 2005-2009, found prevalence of ETF benefits viz. diversified portfolios at lower cost, low expense ratios, reduced tracking error and volatility, to small investors. Narend (2014) however argued in favour of index funds, funds with lower tracking error and a higher Jensen's alpha. On contrary, the author argued for ETFs in terms of active returns recorded by the two funds.

Dellva (2001) in his research endeavour compared the costs incurred in investment into iShares S\&P 500 Index fund, SPDRs and Vanguard Index 500 Fund. The research acknowledged the difference in both, level of investment and holding tenure. ETFs were found to be characterised with lower annual expenses, more so in long-tenure investments. However, Bernstein (2002) claimed that the investor tendency to liquidate investments frequently diminishes the ETF cost advantage.

Elton, Gruber, Comer, \& Li (2002) examined the performance of Standard and Poor's Depository Receipts (SPDR) as against the benchmark S\&P 500 Index. The study found the net asset value as gauged before dividends on underlying securities and management fees to closely match the S\&P Index. Also the price returns of SPDR underperformed the index by 0.28 percent. The principal reasons for such underperformance were fund's expense ratio and investment of dividends received on the underlying securities into non-interest-bearing account. While evaluating the performance of ETFs with closed-end country funds (CEFs), Harper, Madura, \& Schnusenberg (2006) find that ETFs showcase both, higher mean return and excess risk free return to its total risk. Again negative alphas for CEFs suggest the preference for passive investment strategy as in case of ETFs over active investment strategy of CEFs. 
In studies encompassing volatility, Chen \& Huang (2010) utilised the exponential GARCH model to conclude exceptionally good spillover effects from return in Hong Kong and Singapore, while Taiwan's stock index return was recorded to have a strong negative impact on ETF return. Existence of spillover effects on stock index and ETF volatilities were its major findings. The linkages between equity market returns and volatility spillovers in Germany, United Kingdom (UK), China, Russia, and Turkey as investigated by Dedi \& Yavas (2016) during the period March 2011-2016, showed the existence of significant co-movement in returns among the countries in the sample. While highest volatilities were exhibited by Russia and Turkey, UK and the Chinese markets had the lowest. Furthermore, only UK volatility of the market had a positive effect on its future return, vouching for the risk-return trade-off.

The risk-return off demands security returns to inflate with the underlying risk, however since ETFs passively track their benchmark portfolios, the benchmark shall only account for such inflation. The present study thus attempts to examine the impact of volatility and benchmark returns, if any, on the ETF return.

\section{RESEARCH METHODOLOGY}

The motivation behind conduct of the study is to examine the impact of volatility clustering and benchmark portfolio return upon the return of equity exchange traded fund. The sample data on ETFs and Nifty50 index closing prices have been mined from the data archives of National Stock Exchange of India Ltd. At the end of 30th April 2019, 27 equity ETFs were being actively traded on the NSE trading platform, of which 10 ETFs had Nifty50 Index as their underlying portfolio. The sample is confined to ETFs benchmarking the Nifty50 Index. As these schemes vary in their inception dates, the launch dates being in the range of December 28, 2001 to September 03, 2015, the necessary data on closing prices of ETFs and Nifty50 Index have been collected for the period of September 03, 2015 to April 30, 2019 being the date from which the study is undertaken. The collection of data for such period ensures uniformity and subjects the sample variables to identical effect of forces/factors, if any which may influence the sample variables under study. The name, symbol and inception dates of sample exchange traded funds (ETFs) are reported in Table 1.

Table 1: List of Equity ETFs listed on NSE with NIFTY 50 Index as underlying

\begin{tabular}{|c|l|l|c|}
\hline Sr. No. & \multicolumn{1}{|c|}{ ETF Name } & \multicolumn{1}{|c|}{ ETF Symbol } & Launch Date \\
\hline 1 & Birla Sun Life NIFTY ETF & BSLNIFTY & $21-07-2011$ \\
\hline 2 & Edelweiss Exchange Traded Scheme - NIFTY & NIFTYEES & $08-05-2015$ \\
\hline 3 & ICICI Prudential NIFTY ETF & ICICINIFTY & $20-03-2013$ \\
\hline 4 & Kotak NIFTY ETF & KOTAKNIFTY & $02-02-2010$ \\
\hline 5 & MOSt Shares M50 & M50 & $28-07-2010$ \\
\hline 6 & Quantum Index Fund - Growth & QNIFTY & $10-07-2008$ \\
\hline 7 & Reliance ETF NIFTY BeES & NIFTYBEES & $28-12-2001$ \\
\hline 8 & Religare Invesco NIFTY ETF & IVZINNIFTY & $13-06-2011$ \\
\hline 9 & SBI ETF NIFTY & SETFNIF50 & $23-07-2015$ \\
\hline 10 & UTI NIFTY ETF & UTINIFTETF & $03-09-2015$ \\
\hline
\end{tabular}

Source: Compiled from data archives of National Stock Exchange of India Ltd. 
The study incorporates the use of Augmented Dickey Fuller Test (ADF), Autoregressive Conditional Heteroscedastic Model (ARCH), Generalized Autoregressive Conditional Heteroscedastic Model (GARCH) and GARCHin-Mean Model.

\section{Return}

The 10 Exchange traded funds (ETFs) sampled for the current research seek to match the benchmark Nifty50 Index return. The return on each of the time series is computed as the first difference of each day closing prices as follows;

$$
R_{t}=\ln \left(P_{t} / P_{t-1}\right)
$$

Where ' $l n$ ' denotes natural logarithm, ${ }^{\prime} R_{t}{ }^{\prime}$ is daily log return for ' $t$ ' time period, while ' $P_{t}{ }^{\prime}$ and ${ }^{\prime} P_{t-1}{ }^{\prime}$ are daily closing prices of the ETF/Index at two successive days ' $t$ ' and ' $t-1$ ' respectively.

\section{Augmented Dickey-Fuller (ADF) test}

Stationary of time series is a pre-condition for employment of ARCH/GARCH Models used for econometric testing. In fact the use of non-stationary series may lead to spurious regressions. A Stationary series is one with constant mean, covariance and autocovariances for each given lag. In the present research, a unit root test as suggested by Dickey and Fuller (1979) is used to test stationarity of time series.

$$
R_{t}=\delta R_{t-1}+e_{t}, \text { where }-1 \leq \delta \leq 1
$$

In case ' $\delta$ ' is equal one in equation (2), the return series contains unit root and hence non-stationary. ${ }^{\prime} R_{t-1}$ ' denotes return at one lagged time period.

\section{ARCH/GARCH Model}

In view of the fact that ETFs endeavour to replicate its benchmark return, the regression for such process could be modelled as

$$
R_{t}=\beta_{1}+\beta_{2} I_{t}+u_{t}
$$

Where ' $R_{t}{ }^{\prime}$ and ' $I_{t}{ }^{\prime}$ express the ETF return and benchmark Nifty50 return respectively at time ' $t$ '; ' $\beta_{1}{ }^{\prime}$ and ' $\beta_{2}{ }^{\prime}$ are the parameters; and ' $u_{t}$ ' denotes the error term. The rules of Classical Linear Regression Model assume that $u_{t} \sim N\left(0, \sigma^{2}\right)$, that is the error term in equation (3) bears a property of zero mean and constant variance. However in practice it is unlikely for the error variance to be constant over a period of time. Techniques of ARCH/GARCH aid in modelling such heteroscedasticity in error term, thereby highlighting the clustering of volatility in time series. The Autoregressive Conditionally Heteroscedastic $(\mathrm{ARCH})$ Model parameterises the conditional variance $\left(\sigma_{t}^{2}\right)$ of error term $\left(u_{t}\right)$ as a function of its immediate preceding squared error terms as denoted in equation (4).

$$
\sigma_{t}^{2}=\alpha_{0}+\alpha_{1} u_{t-1}^{2}+\cdots+\alpha_{p} u_{t-p}^{2}
$$

' $p$ ' in equation (4) denotes the number of lags of squared errors. Conditional variance is identified as the variance of a random variable for given set of values of one or more variables. Significant values of ' $\alpha_{1}{ }^{\prime}$ and ' $\alpha_{p}{ }^{\prime}$ imply presence of volatility. 
Bollerslev (1986) overcame the limitation of the ARCH model in specifying the value of lags (p) by suggesting the GARCH model, and since then is widely used technique to model volatility. The Generalised ARCH (GARCH) model allows the conditional variance to gather stimulus from both lagged squared error term and previous time period conditional variance as denoted in equation (5).

$$
\sigma_{t}^{2}=\beta_{1}+\beta_{2} u_{t-1}^{2}+\beta_{3} \sigma_{t-1}^{2}
$$

Although several lags may be introduced for both error term and conditional variance in equation (5), the present study employs a GARCH $(1,1)$ model to capture volatility in the ETF return series. Coefficients $\beta_{2}$ and $\beta_{3}$ capture the stimulus to conditional variance by previous squared shocks $\left(u_{t-1}^{2}\right)$ and previous variance $\left(\sigma_{t-1}^{2}\right)$ respectively.

\section{GARCH-in-Mean Model (GARCH-M)}

The finance theory suggests a positive relation between return and risk for a given investment. Thus the return on an asset may be said to be partly determined by its risk too. The GARCH-M model helps to operationalise such concept by incorporating conditional variance as an exogenous variable in defining the time series return. Hence equation (3) is redefined as noted in equation (6)

$$
R_{t}=\beta_{1}+\beta_{2} I_{t}+\beta_{3} \sigma_{t-1}^{2}+u_{t}
$$

If ' $\beta_{3}$ ' in equation (6) is found positive and statistically significant, then keeping the other factors constant, every increased risk/volatility as denoted by conditional variance leads to rise in mean return. Hence the study uses the GARCH$\mathrm{M}$ model to examine the relationship between conditional volatility and ETF return.

\section{RESULTS \& ANALYSIS}

Table 2 reports the descriptive properties for the log-returns of the benchmark Nifty50 and sample ETFs. The mean return of all sample ETFs $(0.02 \%)$ is lower than that of Nifty50 (0.05\%), in fact the ETFs returns range between -0.21 to 0.07 . Such priori estimates suggest variation to conceptual belief of ETFs trying to replicate benchmark return. Furthermore the average variability of return over its mean is higher for ETFs in contrast to the benchmark (standard deviation of 2.14 versus 0.79 ). The skewness and kurtosis numbers signify the sample return series to be asymmetrically distributed. A paired sample t-test supporting the null hypothesis of no difference between benchmark Nifty50 and ETF return is accepted all 10 sample ETFs.

Table 2: Summary Statistics of Sample Data

\begin{tabular}{|l|c|c|c|c|c|}
\hline \multicolumn{1}{|c|}{ Index/ETF } & Mean (\%) & $\begin{array}{c}\text { Standard } \\
\text { Deviation (\%) }\end{array}$ & Skewness & Kurtosis & $\begin{array}{c}\text { t-statistic } \\
\text { (Paired Sample) }\end{array}$ \\
\hline Nifty50 & 0.05 & 0.79 & -0.20 & 4.18 & - \\
\hline BSLNIFTY & 0.03 & 2.49 & -0.34 & 6.45 & -0.19 \\
\hline NIFTYEES & 0.07 & 3.26 & -0.06 & 23.06 & 0.21 \\
\hline ICICINIFTY & 0.04 & 0.99 & -1.04 & 12.85 & -0.09 \\
\hline KOTAKNIFTY & -0.21 & 7.71 & -29.59 & 881.72 & -0.99 \\
\hline M50 & 0.04 & 1.09 & -0.08 & 3.80 & -0.01 \\
\hline QNIFTY & 0.04 & 0.83 & -0.52 & 11.27 & -0.16 \\
\hline NIFTYBEES & 0.05 & 0.75 & -0.27 & 4.24 & 0.61 \\
\hline
\end{tabular}




\begin{tabular}{|l|l|l|l|l|l|}
\hline IVZINNIFTY & 0.05 & 2.32 & -0.23 & 18.04 & 0.07 \\
\hline SETFNIF50 & 0.05 & 1.02 & -0.03 & 27.17 & 0.09 \\
\hline UTINIFTETF & 0.05 & 0.96 & 0.03 & 11.11 & 0.19 \\
\hline
\end{tabular}

Note: '***', ‘**', and '*’ denote significance at 1\%, 5\%, and $10 \%$ level of significance respectively

Source: Compiled using Eviews 8

Table 3: Result of Augmented Dickey-Fuller Unit Root Test

\begin{tabular}{|l|l|l|}
\hline \multicolumn{1}{|c|}{ Index/ETF } & t-statistic & p-value \\
\hline Nifty50 & -28.46 & $0.00 * * *$ \\
\hline BSLNIFTY & -23.78 & $0.00^{* * *}$ \\
\hline NIFTYEES & -22.34 & $0.00^{* * *}$ \\
\hline ICICINIFTY & -32.83 & $0.00^{* * *}$ \\
\hline KOTAKNIFTY & -29.96 & $0.00^{* * *}$ \\
\hline M50 & -40.42 & $0.00^{* * *}$ \\
\hline QNIFTY & -29.68 & $0.00^{* * *}$ \\
\hline NIFTYBEES & -28.74 & $0.00^{* * *}$ \\
\hline IVZINNIFTY & -23.97 & $0.00^{* * *}$ \\
\hline SETFNIF50 & -36.96 & $0.00^{* * *}$ \\
\hline UTINIFTETF & -34.27 & $0.00 * * *$ \\
\hline
\end{tabular}

Note: '***’, ‘**', and '*' denote significance at $1 \%, 5 \%$, and $10 \%$ level of significance respectively

Source: Compiled using Eviews 8

The results of Augmented Dickey-Fuller Test as presented in Table 3, clearly show that in each return series sampled for the study, the null hypothesis of presence of unit root is convincingly rejected. The p-values are all significant at one percent level of significance, this implies that all return series are integrated of order zero, and hence are stationary. This makes it convenient to employ ARCH/GARCH Models.

Table 4: Result of parameter estimates of Volatility Clustering using GARCH Model

\begin{tabular}{|c|c|c|c|}
\hline Dependent Variable & \multicolumn{3}{|c|}{ Independent Variable } \\
\hline ETF & Constant & ARCH (1) & GARCH (1) \\
\hline BSLNIFTY & $\begin{array}{c}0.000 * * * \\
(3.36)\end{array}$ & $\begin{array}{c}0.069 * * * \\
\quad(6.23)\end{array}$ & $\begin{array}{c}0.898 * * * \\
(61.35)\end{array}$ \\
\hline NIFTYEES & $\begin{array}{c}0.000 * * * \\
(16.09)\end{array}$ & $\begin{array}{c}0.057 * * * \\
(19.84)\end{array}$ & $\begin{array}{c}0.934 * * * \\
(456.05)\end{array}$ \\
\hline ICICINIFTY & $\begin{array}{c}0.000 * * * \\
(7.90)\end{array}$ & $\begin{array}{c}0.225 * * * \\
(8.41)\end{array}$ & $\begin{array}{c}0.754 * * * \\
(39.11)\end{array}$ \\
\hline KOTAKNIFTY & $\begin{array}{l}0.003 \\
(0.65)\end{array}$ & $\begin{array}{l}-0.001 \\
(-1.55)\end{array}$ & $\begin{array}{l}0.596 \\
(0.95)\end{array}$ \\
\hline M50 & $\begin{array}{c}0.000 * * * \\
(5.84)\end{array}$ & $\begin{array}{c}0.272 * * * \\
(4.81)\end{array}$ & $\begin{array}{l}0.061 \\
(0.52)\end{array}$ \\
\hline
\end{tabular}




\begin{tabular}{|c|c|c|c|}
\hline QNIFTY & $\begin{array}{l}0.000 \\
(0.71)\end{array}$ & $\begin{array}{l}-0.008 \\
(-0.90)\end{array}$ & $\begin{array}{l}0.476 \\
(0.64)\end{array}$ \\
\hline NIFTYBEES & $\begin{array}{c}0.000 * * * \\
(6.09)\end{array}$ & $\begin{array}{c}0.233^{* * *} \\
(4.91)\end{array}$ & $\begin{array}{c}0.323 * * * \\
(3.37) \\
\end{array}$ \\
\hline IVZINNIFTY & $\begin{array}{c}0.000 * * * \\
(8.58)\end{array}$ & $\begin{array}{c}0.174 * * * \\
(9.57)\end{array}$ & $\begin{array}{c}0.760 * * * \\
(36.50)\end{array}$ \\
\hline SETFNIF50 & $\begin{array}{l}-0.000 \\
(-1.23)\end{array}$ & $\begin{array}{c}0.379 * * * \\
(17.71)\end{array}$ & $\begin{array}{c}0.813 * * * \\
(110.75)\end{array}$ \\
\hline UTINIFTETF & $\begin{array}{c}0.000 * * * \\
(13.09)\end{array}$ & $\begin{array}{c}0.460 * * * \\
(13.11)\end{array}$ & $\begin{array}{l}0.062 \\
(1.12)\end{array}$ \\
\hline
\end{tabular}

Note: 1. Figures in the parenthesis ( ) denote Z-statistic values

2. '***, ' '**', and '*' denote significance at $1 \%, 5 \%$, and $10 \%$ level of significance respectively

Source: Compiled using Eviews 8

The GARCH $(1,1)$ model (results produced in Table 4), widely accepted in academia, provides a better fit to deal with non-negativity constraints while overcoming the limitation of specifying the number of lags to be incorporated in ARCH models. In all ETFs except for KOTAKNIFTY and QNIFTY, the conditional variance collects significant stimulus from its past shock [ARCH (1)]. Responses of variance to its own previous variance [GARCH (1)] are significant in six of ten ETFs at 1 percent level of significance. Furthermore, the sum of ARCH (1) and GARCH (1) coefficients being closer to one for BSLNIFTY, NIFTYEES, ICICINIFTY, IVZINNIFTY and SETFNIF50 signpost enduring effect of exogenous shocks on volatility of ETF return. Thus except for KOTAKNIFTY and QNIFTY, ETFs returns exhibit significant volatility clustering. Volatility clustering refers to the tendency for volatility in financial assets to appear in clusters.

Table 5 reports the slope coefficients for regression (refer equation 6) of ETF return being linearly determined as a combination of benchmark index and conditional variance (risk). Compensation to investors for additional investment risk and time value of money, as propagated by the Capital asset pricing model (CAPM) is immaterial for ETFs as its returns shall ideally match benchmark index returns. Except for KOTAKNIFTY, all other ETF returns significantly depend on tracking index return at 1 percent level of significance. The coefficient for risk (GARCH) shall be insignificant, and indeed is except for ICICINIFTY and NIFTYBEES. Interestingly the GARCH slope coefficients are negative, a sign not justified in empirical framework.

Table 5: Result for determinants of ETF return using GARCH-M Model

\begin{tabular}{|c|c|c|c|}
\hline \multirow{2}{*}{$\begin{array}{c}\text { Dependent Variable } \\
\text { ETF }\end{array}$} & \multicolumn{3}{|c|}{ Independent Variable } \\
\hline & Constant & Nifty & GARCH \\
\hline BSLNIFTY & $\begin{array}{l}0.000 \\
(0.37) \\
\end{array}$ & $\begin{array}{c}0.306^{* * *} \\
(3.40) \\
\end{array}$ & $\begin{array}{l}-0.873 \\
(-0.30) \\
\end{array}$ \\
\hline NIFTYEES & $\begin{array}{l}0.001 \\
(1.06)\end{array}$ & $\begin{array}{c}0.210^{* *} \\
(2.47)\end{array}$ & $\begin{array}{l}-0.948 \\
(-0.56)\end{array}$ \\
\hline ICICINIFTY & $\begin{array}{c}0.000^{* *} \\
(2.02)\end{array}$ & $\begin{array}{c}0.927 * * * \\
(97.98)\end{array}$ & $\begin{array}{c}-6.661 * \\
(-1.94)\end{array}$ \\
\hline
\end{tabular}




\begin{tabular}{|l|c|c|c|c|}
\hline \multirow{2}{*}{ KOTAKNIFTY } & $\begin{array}{c}-0.000 \\
(-0.00)\end{array}$ & $\begin{array}{c}0.887 \\
(0.13)\end{array}$ & $\begin{array}{c}-0.432 \\
(-0.01)\end{array}$ \\
\hline \multirow{2}{*}{ M50 } & & 0.001 & $0.558^{* * *}$ & -11.255 \\
& $(1.25)$ & $(14.68)$ & $(-1.17)$ \\
\hline \multirow{2}{*}{ QNIFTY } & & 0.000 & $0.480^{* * *}$ & - \\
\hline \multirow{2}{*}{ NIFTYBEES } & $(0.74)$ & $(17.70)$ & $\begin{array}{c}0.923 * * * \\
(150.42)\end{array}$ & $\begin{array}{c}-160.07 * * \\
(-2.96)\end{array}$ \\
\hline \multirow{2}{*}{ IVZINNIFTY } & & $0.000^{* * *}$ & $0.359 * * *$ & -2.026 \\
& & 0.001 & $(5.56)$ & $(-0.84)$ \\
\hline \multirow{2}{*}{ SETFNIF50 } & $(1.24)$ & $0.888^{* * *}$ & -3.167 \\
& & $0.000^{* *}$ & $(77.66)$ & $(-0.65)$ \\
\hline \multirow{2}{*}{ UTINIFTETF } & & 0.000 & $0.831 * * *$ & -10.483 \\
& & $(1.41)$ & $(36.41)$ & $(-1.48)$ \\
\hline
\end{tabular}

Note: 1. Figures in the parenthesis ( ) denote Z-statistic values

2. '***', '**', and '*' denote significance at $1 \%, 5 \%$, and $10 \%$ level of significance respectively

Source: Compiled using Eviews 8

\section{CONCLUSIONS}

The paper investigated the dependence of ETF return on its benchmark index return and volatility. Conceptual framework of structuring of ETF suggests its return be matched to benchmark index, as the portfolio manager passively invests all investor funds into stocks comprising the benchmark portfolio. This phenomenon infers existence of no diversification benefits for any additional risk imposed. Daily log returns for the period September 03, 2015 to April 30, 2019 were amassed to examine the impact of volatility clustering and benchmark portfolio return upon the return of equity exchange traded fund. Descriptive analysis confirmed ETFs having lower average return vis-à-vis benchmark Nifty50 return; however t-test for difference in mean returns suggested otherwise equating both pairs of return. The results of Augmented Dickey-Fuller Test fulfilled the condition that log return data considered for the study followed no random walk, hence suitable in application of GARCH model to confirm the existence of volatility clustering in return time series. Eight of ten ETFs returns were found significant to exhibit clustered presence of volatility. In attempt to explore whether ETF return is a function of risk besides being determined by changes in benchmark index return, the study found no influence of volatility on mean ETF return. Analogous to theory, ETF return is a function of benchmark Nifty50 return, however the non-significant volatility coefficient concludes not feedback from conditional variance on mean ETF return. As Dedi \& Yavas (2016) suggest increased volatility leads to increased future ETF returns, the present study with insignificant volatility coefficients in the GARCH-M model report on the contrary.

\section{REFERENCES}

1. Aber, J. W., Li, D., \& Can, L. (2009). Price volatility and tracking ability of ETFs. Journal of Asset Management, 10(4), 210221. [In text citation: Aber, Li and Can 2009]

2. Athma, P., \& Kumar, R. K. (2011). Etf vis-à-vis index funds: an evaluation. Asia Pacific Journal of Research in Business Management. 2(1), 188-205. [In text citation : Athma and Kumar (2011)] 
3. Bernstein, P. J. (2002). A primer on exchange-traded funds, Journal of Accountancy, 193, 38-41. [In text citation : Bernstein (2002)]

4. Bollerslev, T. (1986). Generalized autoregressive conditional heteroskedasticity. Journal of Econometrics, 31(3), 307-327. [In text citation : Bollerslev (1986)]

5. Chen, J. H., \& Huang, C. Y. (2010). An analysis of the spillover effects of exchange-traded funds, Applied Economics, 42(9), 1155-1168. [In text citation: Chen and Huang (2010)]

6. Chu, P. K. (2011). Study on the tracking errors and their determinants: evidence from Hong Kong exchange traded funds. Applied Financial Economics, 21(5), 309-315. [In text citation : Chu 2011]

7. Dedi, L., \& Yavas, B. F. (2016). Return and volatility spillovers in equity markets: an investigation using various GARCH methodologies. Cogent Economics \& Finance, 4(1), 1266788. [In text citation : Dedi and Yavas (2016)]

8. Dellva, W. L. (2001). Exchange-traded funds not for everyone, Journal of Financial Planning, 14, 110-124. [In text citation : Dellva (2001)]

9. Dickey, D. A., \& Fuller, W.A. (1979). Distributions of the estimators for autoregressive time series with a unit root. Journal of the American Statistical Association, 74(366a), 427-431. [In text citation : Dickey and Fuller (1979)]

10. Elton, E. J., Gruber, M. J., Comer, G., \& Li, K. (2002). Spiders: where are the bugs?. The Journal of Business, 75(3), $453-472$. [In text citation : Elton et al. (2002)]

11. Harper, J. T., Madura, J., \& Schnusenberg, O. (2006). Performance comparison between exchange-traded funds and closedend country funds. Journal of International Financial Markets, Institutions and Money, 16(2), 104-122. [In text citation : Harper et al. (2006)]

12. Lee, C. F. \& Rui, O. M. (2000). Does trading volume contain information to predict stock returns? evidence from China's stock markets. Review of Quantitative Finance and Accounting, 14(4), 341-360. [In text citation : Lee and Rui (2000)]

13. Lin, A., \& Chou, A. (2006). The tracking error and premium/discount of Taiwan's first exchange traded fund. Web Journal of Chinese Management Review, 9(3), 1-21. [In text citation : Lin and Chou 2006]

14. Mahajan, S., \& Singh, B. (2008a). An empirical analysis of stock price-volume relationship in Indian stock market. Vision, 12(3), 1-13. [In text citation: Mahajan and Singh (2008a)]

15. Narend, S. (2014). Performance of etfs and index funds: a comparative analysis (Unpublished Post Graduate Student Research Project), Department of Management Studies, Indian Institute of Technology, Madras. [In text citation : Narend (2014)]

16. Richardson, G., Sefcik, S. E., \& Thompson, R. (1987). A test of dividend irrelevance using volume reaction to a change in dividend policy. Journal of Financial Economics, 17(2), 313-333. [In text citation : Richardson et al. (1987)]

17. Roll, R. (1992). A mean/variance analysis of tracking error. The Journal of Portfolio Management, 18(4), 13-22. [In text citation : Roll (1992)]

18. Rompotis, G. G. (2009b). Performance and trading characteristics of iShares: an evaluation. The ICFA Journal of Applied Finance, 15(7), 24-39. [In text citation : Rompotis 2009b]

19. Singh, J., \& Kaur, P. (2016). Tracking efficiency of exchange traded funds (ETFs): empirical evidence from Indian equity ETFs, Paradigm, 20(2), 176-190. [In text citation: Singh and Kaur (2016)] 
20. Sinha, S., \& Dutta, M. (2013). Performance analysis of returns of Goldman Sachs gold exchange traded fund. Global Journal of Management and Business Studies, 3(7), 793-800. [In text citation : Sinha and Dutta 2013] 